Pragmatist Legacies in Aesthetics

\title{
A Proposed Taxonomy of Realism in Conceptual Frameworks
}

Paolo Valore

\section{(2) OpenEdition \\ 12 Journals}

Electronic version

URL: http://journals.openedition.org/ejpap/2331

DOI: 10.4000/ejpap.2331

ISSN: 2036-4091

\section{Publisher}

Associazione Pragma

\section{Electronic reference}

Paolo Valore, "A Proposed Taxonomy of Realism in Conceptual Frameworks", European Journal of Pragmatism and American Philosophy [Online], XIII-1 | 2021, Online since 02 April 2021, connection on 04 April 2021. URL: http://journals.openedition.org/ejpap/2331 ; DOI: https://doi.org/10.4000/ejpap. 2331

This text was automatically generated on 4 April 2021.

\section{$\Theta \Theta \Theta$}

Author retains copyright and grants the European Journal of Pragmatism and American Philosophy right of first publication with the work simultaneously licensed under a Creative Commons AttributionNonCommercial-NoDerivatives 4.0 International License. 


\title{
A Proposed Taxonomy of Realism in Conceptual Frameworks
}

\author{
Paolo Valore
}

\section{A Confusing Picture}

1 In "Things and Their Place in Theories," Quine labels himself as "a robust realist" for his "unswerving belief in external things - people, nerve endings, sticks, stones" as well as "atoms and electrons and [...] classes," in connection with his naturalism and his conception of science (Quine 1981: 21). According to this picture, being a "realist" means having a certain belief in the nature of the kinds of entities we are assuming, such as physical objects or abstract entities; and it is Quine's "unswerving belief" what makes his realism "robust." Curiously enough, both his conception of entities, physical or abstract, and his naturalistic conception of science granted Quine the label of "antirealist." According to Peter Hylton, for instance, in Quine's philosophy "there is no more to an object than its role in the theory," and "we can systematically switch objects from role to role. The result is ontological relativity. [...] The possibility of this sort of switching, if granted, seems to undermine realism by indicating that we do not really know what we are being realistic about; we feel as if we are in the odd position of insisting that something must exist but having to acknowledge that we cannot say what" (Hylton 2004: 144). Again, according to Hylton, being an "antirealist" means having a certain belief in the nature of the kinds of entities we are assuming. The situation gets even more confused when we recall that, notwithstanding the "robust realism" Quine ascribed to himself, he was criticized by Armstrong (1980) for his antirealistic rejection of universals, for instance through the refusal of an ontological commitment to predicates. According to Armstrong, Quine is giving to predicates "what has been said to be the privilege of the harlot: power without responsibility. The predicate is informative, it makes a vital contribution to telling us what is the case, the world is different if it is different, yet ontologically it is supposed not to commit us. Nice work: if you can get it" (Armstrong 1980: 443). Armstrong in turn describes himself as a realist thanks to his Platonic belief in the existence of universals, but 
Armstrong himself has been considered an "anti-realist" (in ontology, or perhaps metaphysics) for his rejection of Platonic uninstantiated universals. This gets all messed up, when we consider that, according to the literature, being a Platonist means being a realist in ontology (and perhaps in metaphysics) and that Platonism (together with all its Idealistic reworked versions) is considered the most paradigmatic version of the rejection of realism (taken as anti-idealism).

\section{A Meta-Philosophical Approach}

One of the complications of a clear evaluation of different positions in metaphysics and ontology is discrepancy in terminology and variance, if not incongruity, of basic concepts associated to relevant notions. This is a common problem in philosophy, but it seems that it has been exacerbated in recent debates about different clusters of positions called "realism." The topic of realism and anti-realism is clearly central in many contemporary debates, especially in pragmatism and neo-pragmatism and American philosophy in general (e.g., Peirce, Sellars, Dummett, Putnam, ...), not to mention ontology, philosophy of mathematics (Platonism, fictionalism, ...) and so on. Evidently, a significant reconstruction of the various systems (not even of the most important authors) and the many possible foundations and justifications of "realism" is out of the scope of this paper (a well-done comprehensive synopsis of versions of "realism" can be easily found in several other papers and encyclopedia entries, for instance Miller 2019). Instead of trying to infer a definition of "realism," as if by induction, from the countless pictures given by philosophers identifying (or identified by others) as "realists" in the history of philosophy or in a catalogue of current debates, here I offer a taxonomy provided by a conceptual analysis of the notion of "realism" in what I think are its sub-concepts, recognizing three different conceptual frameworks.

The assessment of the notion I am trying to carry out here will be strictly delimited and essentially framed within the bounds of conceptual analysis, will be meta-philosophical in essence, and will not engage in a presentation of what I may judge are the most relevant philosophical positions nor will it engage in a discussion or an evaluation of the best arguments for or against a particular philosophical version of what is called "realism."

\section{How not to Confuse Three Different Kinds of Confusion}

4 Philosophers and historians of philosophy tend to assume that they have an intuitive grasp on the notion of realism and on what they mean when they label some other philosophers, or themselves, as realist. Unfortunately, when we try to spell out the basic intuition inherent in this concept, we meet a significant variance in the core meaning. Such a variance in the concept of "realism" can be understood in (at least) three different ways, the first two of which are not directly my focus here (even though they can still play a secondary role at the level with which I am concerned). 


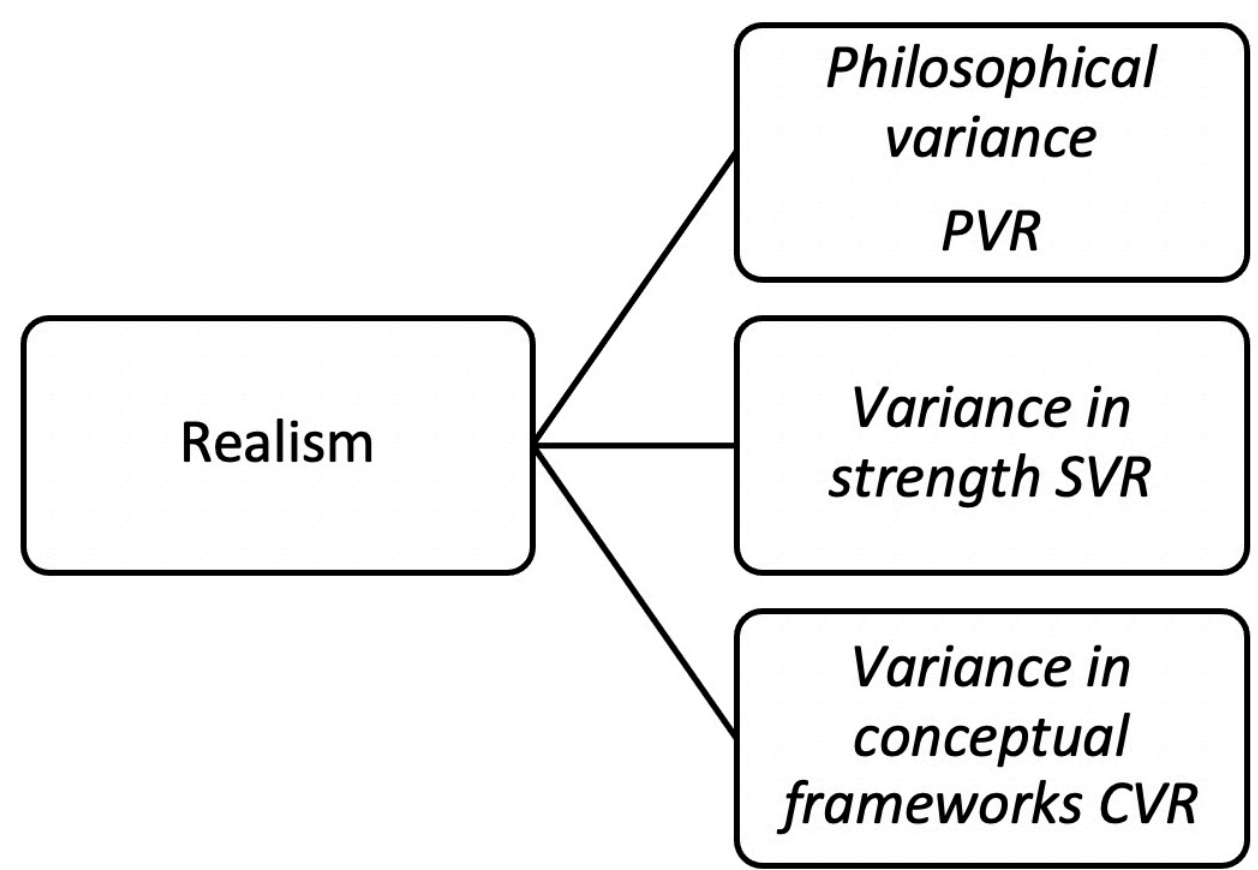

Three kinds of variance in "realism"

5 Firstly, the confusion in terminology can be trivially connected with the fact that philosophers may request different sets of conditions in order for a philosophical position to be acknowledged as actual "realism" or a good version of realism. In this first sense, it seems that the variation in the meaning associated with the concept of "realism" is a variation among different realist philosophical systems. The clearest way we encounter this variance is in the diachronical consideration of philosophy: for instance, when we realize that the "realism," let us say, Nicolai Hartmann had in mind was obviously different than the "realism" Herbart defended. This seems related to the difference of philosophical theories rather than a stratification of different core meanings associated to the very concept of "realism." The clarification required to explicate the different meanings of Hartmann's realism and Herbart's realism is a clarification of their philosophical theories rather than a conceptual analysis of the notion of realism as such. I call this divergence the philosophical variance in the meaning of realism (PVR), as it involves different conceptions of realism as a whole philosophical system.

6 The second one is the contrast among the set of conditions requested to be a realist of the correct kind, which can be expanded, modified or contracted according, again, to the choice of a particular conception, and perhaps to a particular philosophical "taste," with no need to recall a whole philosophical system as in PVR. For instance, we may distinguish an "external realism," an "internal realism," or a "naïve realism." This doesn't recap the whole philosophy of a particular thinker or a particular philosophical school, as it is the case with "Herbart's Realism" or "Marx' Realism" and gets closer to a general definition (or, it seems, a cluster of different definitions) of what is considered essential to be a realist. Still it requires a proper version of realism as opposed to other, less satisfactory versions of weaker realism. I call this divergence the variance in strength in the meaning of realism (SVR), as it distributes kinds of realism on a scale and picks 
the correct version of realism assigning the label of actual realism to a certain point in the series.

7 The third sense of the variance that I have in mind does not involve the request of actuality, as in the previous two cases. This is why I think it is connected at a deeper level to the core meaning of the very notion of "realism" rather than the particular, better or worse, form of a philosophical version of realism. This third sense can be, for instance, clarified in connection to the correlated concepts we associate to the notion of "realism" and it seems linked to the particular framework in which we are using the notion. For instance, in ontology we contrast being a realist with being an antirealist (or a nihilist) while in epistemology we tend to contrast being a realist with being an idealist. I call this divergence in the meaning of realism the variance in conceptual frameworks (CVR), as it involves different roles of the notion of "realism" in different theoretical contexts.

It is the clarification of CVR that is my focus here, but I may still use PVR and SVR (mainly, by contrast) in order to get my results. There have obviously been many attempts at a clarification of the notion in realism but contributions are usually devoted to illustrating a particular philosophical stance in the philosophical arena, in the sense of PVR and SVR, or to offering a defense of (or an attack to) a particular version of realism rather than clarifying the variance of the core notions implied in different usages, as in CVR.

Puzzlingly, exploiting the variance in the third sense can be a philosophical tool, wittingly or not, in order to show the weakness of the philosophical notions we want to discredit or to attempt an objective evaluation of the costs and benefits of a philosophical theory. Nonetheless, the clarification required in CVR does not, as such, need to be connected to one form or another of the philosophical positions called "realism."

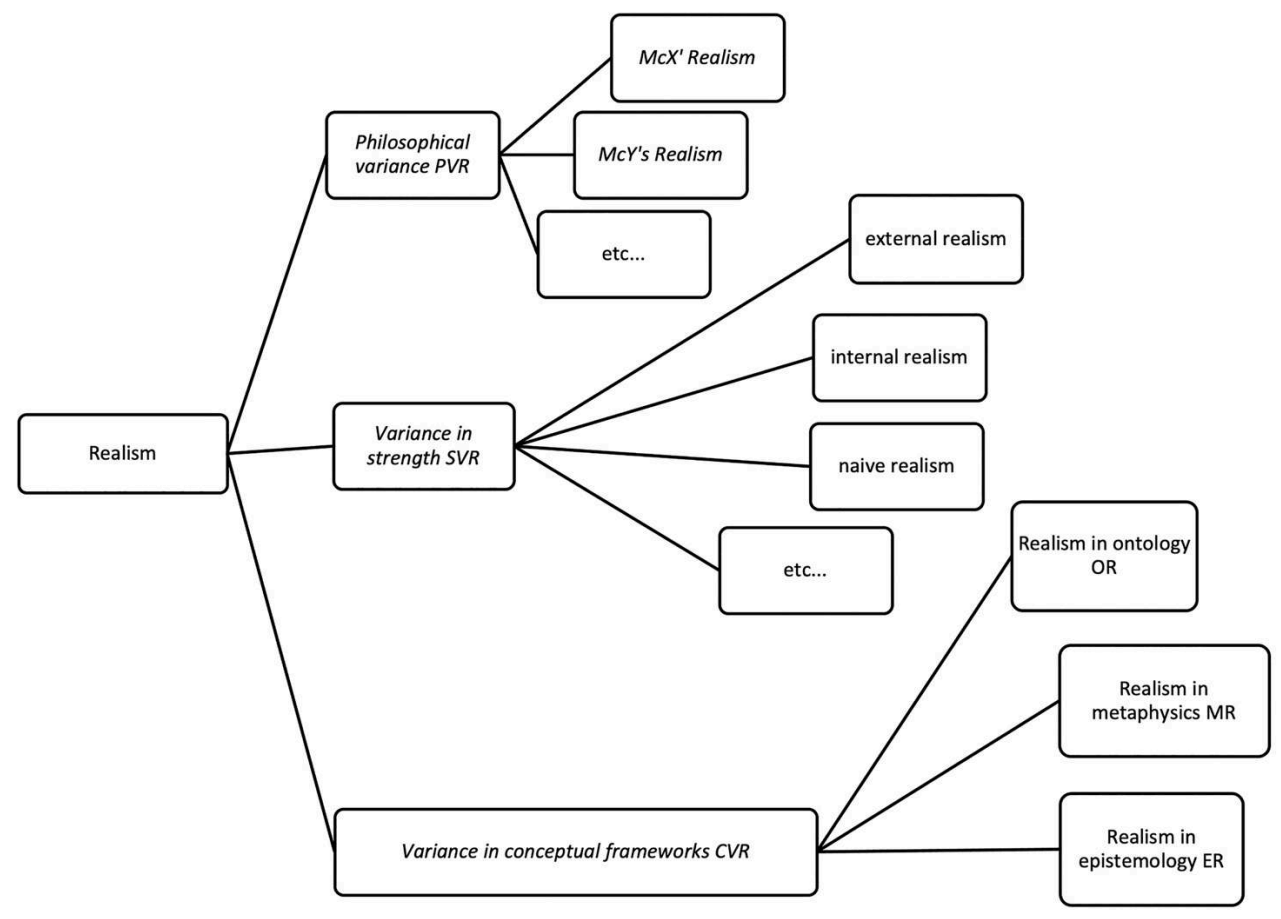




\section{Toward a Taxonomy for CVR}

10 Some attempts at recommending a taxonomy for realism are available in the literature, usually to articulate different forms of "scientific realism" (e.g. Putnam 1982; Horwich 1982; Merrill 1980), but with significant differences. Given that my approach here is completely alternative, I will not discuss those taxonomies here.

It is common to distinguish three forms of realism, and my proposal here also assumes three kinds of realism.

1) Most of the conceptions that we are used to call "realist" fall under the category of what I call "realism in epistemology" or "epistemological realism" (ER). The basic assumption of ER consists in the theses that i) which and how many entities exist and which and how many (relevant) properties they exhibit is independent from the activity of a cognitive agent or a conceptual scheme or the logical structure of a language and the ideology of a certain theory, and ii) our knowledge consists of adequately capturing or mirroring such independent reality. In this sense for instance, Kant is not a realist.

2) A completely different notion of realism (sadly, sometimes confused with the previous one) is "realism in ontology" or "ontological realism" (OR). The basic assumption of OR consists in the thesis that a certain kind of entity (or certain kinds of entities) is (are) to be considered existent and counted in our inventory of the world. In this sense, for instance, Kant is a realist about mathematical objects, since they are, as objects, on a par with any other object, empirical or not, and they are constituted thanks to the correct application of the set of a priori concepts to the pure intuitions of space and time. And according to Kant, there is no other meaningful way to be an object; therefore, mathematical objects are legitimately included in our inventory of kinds of entities.

14 3) A third notion, one that requires more subtle notions to be distinguished from the previous two is "realism in metaphysics" or "metaphysical realism" (MR). According to $\mathrm{MR}$, being realist does not involve the question whether some entities exist, but how they exist. In general, in any form of realism in the sense of MR, the notion of "reality" is assumed to play an essential role in metaphysical explanations. It may sound that MR can be reduced to ER, since we may offer a picture of MR according to which, for instance, truth consists in a correspondence relationship between our assertions/ theories, on one side, and reality at some fundamental level, on the other side. Nonetheless, one can be realist in the sense of MR, which is a thesis about truth and the actual nature of reality at a deep level, and still not be a realist in the sense of ER, which is a thesis about knowledge, if one assumes a discrepancy between our cognitive abilities and reality as it is metaphysically. For instance, one may assume that knowledge does not adequately capture or mirror reality as it is, or that doesn't reach the fundamental level of reality. In this sense, a philosopher following Quine's approach to ontological questions as quantificational questions or assuming a (neo-)Carnapian approach to questions of existence, is not a realist, as she wouldn't assume any notion of "reality" in assigning the existence to a class of entities required by our sentences (saying for instance that "universals and properties exist" does not involve the notion of reality). Again, in this sense, a philosopher following Kant, who is 
not to be considered an ER realist and is to be considered an OR realist, can be considered a MR realist if she stresses the relevance of the category of "reality," which is a pure concept of our understanding and it is essential to constitute the experience in the form we can have it. Protesting that "reality" is now a category of the understanding does not invalidate the metaphysical essential role of this notion, but just stresses the epistemological role of the cognitive agent in building our experience and our knowledge (invalidating ER and not MR, but ER wasn't assumed anyway from the very beginning). Actually, the same philosopher will not be considered a MR realist if she assumes a notion of truth as pure internal coherence without any form of correspondence to a reality, let's say in some version of Pure Idealism. However we decide to characterize this philosopher, based on the particular form of Kantianism she decides to adopt, it should be clear that being or not a realist in the sense of MR does not involve any revision of our classification of her as a realist in the sense of ER or OR.

To sum up the variances between different notions of realism in different conceptual frameworks, I find it useful to recall the opposition between Plato and Aristotle. Aristotle is commonly contrasted with Plato in terms of realism and antirealism. Clearly, this cannot be in the framework of MR: both Plato and Aristotle are MR realists since they share the typical classical Greek stand in metaphysics that wasn't really challenged until the epistemological doubt of modern times and which assumes a fundamentally natural correspondence between episteme and reality as it is. We can more accurately state their difference articulating it in terms of ER, and more precisely in terms of the notion of "independence" that we used in the definition of ER: Plato assumes that ordinary objects of our empirical knowledge are dependent on Ideas, while Aristotle denies this dependence. What is interesting is that, in terms of OR, for instance regarding abstract objects, it is Plato who is the OR realist (abstract objects exist regardless of their exemplifications) and Aristotle who is the OR antirealist (abstract objects exist exclusively in virtue of individuals that exemplify them).

\section{Local and Global Realism}

Philosophers speak in terms of local and global realism meaning that someone may be a realist in a particular area (e.g. realist about ethics) or kinds of entities (for instance, realist about numbers) or a realist in a more comprehensive sense (see, for instance, Valore 2016, ch. 2). This distinction intersects the previous taxonomy.

ER and MR can be sustained locally or globally. For instance, we can be radical ER realists and assume that anything we know represents an independent reality. Or else, we can locally be ER realists distinguishing sectors of knowledge with different epistemological qualities. Again, we can be radical MR realists and assume that any notion of truth must conform to a correspondence to a notion of reality metaphysically charged. Or else, we can be locally MR realists, assuming this view stands just at some level of reality, for instance at the fundamental level of atoms and void if we are atomistic in the sense of Democritus but not at the level of ordinary objects. Still, some philosophers may disagree, as for them it may be difficult to accept the idea that truth is not defined independently from the contexts of utterance.

On the other hand, it is difficult to make sense of a global anti-realism in the sense of OR. An ontological realist grants existence to a certain kind of entities, meaning that they are not reducible, i.e. they are not dispensable. Some entities, however scarce, 
must be acknowledged (let us say, at least the Self, if you are a solipsistic idealist). The only possibility for a global antirealism in OR seems the rejection of any ontological claim, deflating ontology and/or disposing it as meaningless. However, even the universal rejection of any realism in the sense of OR shouldn't count as an OR antirealistic position, i.e. for a positive eliminativist claim. This is, for instance, clear for a Neo-Carnapian approach, such as the one in Hirsch 2009: he takes for granted that "the world and the things in it exist for the most part in complete independence of our knowledge or language" (ibid.: 232) assigning to himself the label of realist (in my sense of ER); but he denies that ontological disputes are anything more than merely verbal disputes, being in this neither a realist nor an antirealist (in my sense of OR). The global rejection of realism in the case of OR could more properly be labelled as meta-ontological antirealism. In general, it may be useful to recall that the notion of realism we are dealing with here is located at the level of the first order debate, whether certain entities exist, and not at the meta-theoretical level, whether the question about certain entities is meaningful (more on this in Tahko 2015; Valore 2018). For instance, Carnap and Quine may share the same local ontology but disagree at the metaontological level. Therefore, characterizations of OR offered in terms of meaningfulness of ontology ("Ontological Facts are Objective," or "Ontological Disputes Are Serious," see Jenkins 2010) or the rejection of quantifier variance ("Ontological Best Quantifier Meaning," again in Jenkins 2010) should be rejected here, as clearly expressed at the metatheoretical level. This is also the case for the characterization of OR provided in Sider 2009 , according to which ontological realism amounts exactly to univocalism about quantification.

19 Taking the notion of a global OR antirealistic position off the table, can we make sense of a global OR realism? Notwithstanding Quine's joke at the beginning of Quine 1948, nobody really answers the question about what is there saying "everything," at least not if this means that we are never excluding anything at all from our inventory. Excluding both global antirealism and global realism, we can conclude that any OR realism is a form of local realism and any OR antirealism a form of local antirealism. Philosophers are typically OR realists and OR antirealists at the same time regarding different kinds of entities (for instance, a common position among philosophers is to be realists regarding ordinary objects and antirealists about fictional characters, or realists regarding existent objects and antirealists about non-existent or mere possible objects).

\section{CVR and Metaphysical Grounding}

Galimberti 2019 was kind enough to discuss my proposal, interestingly connecting it to the recent debate about metaphysical grounding. In general, any philosopher working within the grounding paradigm is a MR realist, since the main point of grounding theory is to vindicate a metaphysically charged notion of reality. Galimberti wonders whether a grounding theorist is necessarily an ER realist, deciding that it's not the case: for instance, Jonathan Schaffer seems to be, Kit Fine seems not to be.

21 In the case of Schaffer, the taxonomy provided for CVR may help in stating his position about fundamentality. Schaffer 2009 holds an OR permissivist position: many things like numbers, universals, fictional characters exist., leaving open the question of how they exist. 

relevant for the question of realism, Fine does not consider the notion of grounding necessarily involved with a particular realist view. According to Fine 2001 the metaphysical dependence relationship that the notion of grounding expresses can be assumed without further commitments in terms of independence from theories and languages: the dependence relationship may hold between worldly facts and entities or merely within a language between statements and propositions. This conception of grounding keeps the question of realism, in the sense of ER, open.

I am myself convinced that the taxonomy here provided is expressive enough for a fine-grained articulation of different philosophical positions in the recent debate, including the question of metaphysical grounding, without the need to be judgmental about what an actual or genuine form should be. Being this tool meta-philosophical by its own nature, I strongly hold its non-judgmental character a theoretical value.

\section{BIBLIOGRAPHY}

ARMSTRONG David M., (1980), “Against Ostrich Nominalism: A Reply to Michael Devitt,” Pacific Philosophical Quarterly, 61, 440-9.

CHALMERs David, MANLey David \& Ryan WASSERMAn (eds), (2009), Meta-Metaphysics: New Essays on the Foundations of Ontology, Oxford, Oxford University Press.

FINE Kit, (2001), The Question of Realism, in Philosophers' Imprint, 1 (1), 1-30.

GALIMBERTI T. F., (2019), Grounding as Explanatory Relation: The Structure of Reality and the Question of Metaphysical Realism, University of Milan, MA dissertation.

HIRSCH Eli, (2009), "Ontology and Alternative Languages," in D. Chalmers, D. Manley \&

R. Wasserman (eds), Meta-Metaphysics: New Essays on the Foundations of Ontology, Oxford, Oxford University Press, 231-59.

HORWICH Paul, (1982), “Three Forms of Realism,” Synthese, 51 (2), 181-201.

HYLTON Peter, (2004), "Quine on Reference and Ontology," in R. F. Jr. Gibson (ed.), The Cambridge companion to Quine, Cambridge, Cambridge University Press, 115-50.

JENKInS Carrie S., (2010), “What Is Ontological Realism?,” Philosophy Compass, 5 (10), 880-90.

MERRILl Gary H., (1980), “Three Forms of Realism,” American Philosophical Quarterly, 17 (3), 229-35.

MILLER Alexander, (2019), "Realism," in E. N. Zalta (ed.), The Stanford Encyclopedia of Philosophy (Winter 2019 Edition). Online: (https://plato.stanford.edu/archives/win2019/entries/realism/).

PUTNAM Hilary, (1982), “Three Kinds of Scientific Realism,” The Philosophical Quarterly (1950-), 32

(128) (Special Issue: “Scientific Realism”), 195-200.

QUINE Willard Van Orman, (1948), “On What There Is," The Review of Metaphysics, 2, 21-3. Reprinted in Id., From a Logical Point of View. Nine Logico-Philosophical Essays, Cambridge, Mass., Harvard University Press (1953); 2nd rev. Ed. 1961, 1980

European Journal of Pragmatism and American Philosophy, XIII-1 | 2021 
QUINE Willard Van Orman, (1981), "Things and Their Place in Theories," in Id., Theories and Things, Cambridge, Mass., The Belknap Press of Harvard University Press, .

SCHAFFER Jonathan, (2009), “On What Grounds What,” in D. Chalmers, D. Manley \&

R. Wasserman(eds), Meta-Metaphysics: New Essays on the Foundations of Ontology, Oxford, Oxford University Press, 347-83.

SIDER Theodore, (2009), “Ontological Realism,” in D. Chalmers, D. Manley \& R. Wasserman(eds), Meta-Metaphysics: New Essays on the Foundations of Ontology, Oxford, Oxford University Press, 384-423.

TAHKo Tuomas, (2015), An Introduction to Metametaphysics, Cambridge, Cambridge University Press. VALORE Paolo, (2016), Fundamentals of Ontological Commitment, Berlin/Boston, W. de Gruyter. VALORE Paolo, (2018), "The Quest for Higher Order Criteria for Meta-Ontology: Metaphysics Vindicated," Philosophy. Journal of the Higher School of Economics - фИлософия ЖУРНАЛ ВЫСшЕЙ школы экономики, I.4, 13-26.

\section{ABSTRACTS}

One of the complications of a clear evaluation of different positions called "realism" in metaphysics and ontology is discrepancy in terminology and variance of basic intuitions inherent this notion. I recommend a taxonomy that distinguishes three kinds of variance: variance in the sets of conditions for a philosophical position to be acknowledged as actual realism, variance in strength and variance in conceptual frameworks. Within this last case, I propose to differentiate realism in epistemology, in ontology, and in metaphysics, intersecting these three variants with the local/global realism dichotomy. The taxonomy here provided aims at being metaphilosophical; expressive enough for a fine-grained articulation of different philosophical positions in the recent debate, including the question of metaphysical grounding; and impartial, with no need to be connected to the defense of one form or another of the philosophical positions called "realism."

\section{AUTHOR}

\section{PAOLO VALORE}

Università degli studi di Milano

paolo.valore[at]unimi.it 